\title{
Deneyimli bir eğitici gözünden Türkiye'de ortopedi ve travmatoloji uzmanlık eğitimi - gelinen nokta ve geleceğe yönelik öneriler
}

\author{
An expert view on orthopaedic residency training in Turkey: \\ Current situation and future trends \\ Mehmet Demirhan* \\ İstanbul Tıp Fakültesi Ortopedi ve Travmatoloji Anabilim Dalı Öğretim Üyesi (Emekli)
}

\section{Giriş}

Türkiye'de, tüm derneklerde eğitimin standardizasyonu ve tüm ülkede aynı seviyede uzman yetiştirebilme çabaları 1996 yılından itibaren başlamıştır. Türk Ortopedi ve Travmatoloji Birliği Derneği de, 2001 yılında kurmuş olduğu Türk Ortopedi ve Travmatoloji Eğitim Konseyi (TOTEK) ile bu konuda çabalarını hayata geçirmiş̧ir. ilk yıllardaki kuruluş aşamasını hızla tamamlayıp yönergelerini oluşturarak, 2003 yılında ilk sınavını gerçekleştirmiştir. Türkiye'deki eğitimin nasıl olması gerektiğini sorgularken dünyadaki iki öncü ülkeyi incelemek gereklidir: Amerika Birleşik Devletleri ve İngiltere. Bu ülkeler TOTEK'in kuruluşunda da örnek olarak alınmıştır. Avrupa'nın diğer ülkelerinde de uzmanlık eğitiminin standardizasyonu için bu ülkelerin örnek alındığı görülmektedir.

\section{TÜRKIYE'DE SAĞLIK EĞiTiMi VE INSAN GÜCÜ DAĞILIMI}

Türkiye'de 2014 Şubat ayında, Yüksek Öğretim Kurulu, Sağlık Bakanlığı, Maliye Bakanlığı ve Kalınma Bakanlığı tarafından açıklanan Türkiye'de Sağlık Eğitimi ve Sağlık İnsan Gücü Durum Raporu'na göre, Sağlık Bakanlığı Hastanelerinde 74.562, Üniversite Hastanelerinde 28.283 ve Özel Hastanelerde 26.538 hekim çalışmaktadır. Yüz bin kişiye düşen hekim sayısı, Avrupa Birliği (AB) ülkelerinde ortalama 346 iken, ülkemizde 171'dir. Uzman hekim açısından bakıldığında da, AB ortalaması olan 267 hekime kıyasla, aynı nüfusa Türkiye'de 96 uzman hekim düşmektedir. Tıpta uzmanlık eğitimini almakta olanların sayısı, 2003'ten 2012 yilına kadar, 15.888'den 20.183'e, tamamlayanların sayısı ise 2.408 'den 4.228 'e yükselmiştir. Bu artışa rağmen, uzmanlık eğitiminde standardizasyon ve merkezlerin akreditasyon çalışmalarının aynı hızda ilerlemiyor oluşu önemli bir sorun olarak karşımıza çıkmaktadır. Ortopedi ve travmatoloji alanında, 20092013 yılları arasında Tıpta Uzmanlık Sınavı ile alınan asistan sayısı; 2009 yılında 195, 2010 yılında 201, 2011 yılında 185, 2012 yılında 189 ve 2013 yılında 205'tir. Avrupa Birliği ülkelerinde 100.000 kişiye ortalama 8,2 ortopedi ve travmatoloji uzmanı düşmekteyken, ülkemizde bu sayı 3,6'dır. ${ }^{[1]}$

\section{ORTOPEDI VE TRAVMATOLOJI UZMANLIK EĞiTIMINDE INGILTERE VE AMERIKA BIRLEŞiK DEVLETLERi ÖRNEĞi}

Dünyada ortopedi eğitimi coğrafyaya göre farklılıklar göstermektedir. ${ }^{[2]}$ İngiltere son yıllarda, hem eğitimin içeriği hem de eğitim için ayrılan saatler açısından önemli değişimler geçirmiştir. Avrupa'da çalışanların saatlerini sınırlayan yeni bir düzenlemeye bağlı olarak, 2009'dan beri asistanların 8 yıl boyunca toplam eğitim saati \%44 azalma ile 32.000 'den 18.000 'e gerilemiştir.

İngiltere'de tıp fakültesini takiben öğrenciler iki farklı şekilde eğitim görmektedirler. Artık yeni asistan alınmayan eski sistemde, tüm öğrenciler çeşitli aşamalardan geçerek eğitimlerini tamamlamaktadırlar. Bu sistemde herhangi bir yeterlilik ölçümü yapılmamaktadır. Daha güncel olan yeni düzende ise iki yıllık temel eğitimi takiben, aşamalar arasında yeterliliğin ölçüldüğü ve temel eğitimden ayrı bir şekilde alınan ileri düzey eğitim paketleri kullanılmaktadır. İleri düzey eğitimin ortalarından itibaren, eğitim süreci daha fazla yapılandırılmış ve odaklanmış bir şekil almakta, travma ve elektif ortopedik cerrahileri içermekte ve Ulusal Ortopedi Müfredatı'na uygun şekilde gerçekleştirilmektedir. Öğrenciler, eğiticileri tarafından gerçekleştirilen olağan değerlendirmelerin yanında, Royal College of Surgeons

- Iletişim adresi: Prof. Dr. Mehmet Demirhan, Koç Üniversitesi Tıp Fakültesi, Ortopedi ve Travmatoloji Anabilim Dalı, İstanbul e-posta:mdemirhan@ku.edu.tr; demirhanms@gmail.com

- Geliş tarihi: 24 Ekim 2014 Kabul tarihi: 24 Ekim 2014 
tarafindan gerçekleştirilen ve iki aşamadan oluşan yeterlilik sınavını da almaktadırlar. Yan dal yeterliliği, bir dizi daha ileri kıdem gerektiren pozisyonlar ve eğitimler ile elde edilmektedir. Çalışma saatlerinin sınırlandırılması, eğitim kalitesinin düşeceği yönde kaygıların oluşmasına neden olmuştur. 2012'de Association of Surgeons in Training, 48 saat olan haftalık çalışma süresinin 65 saat olacak şekilde esnetilmesi talebinde bulunmuştur. Zaten halihazırda, asistanlar boş günlerinde de $\% 72$ oranında hastaneye gelerek eğitimlerine devam etmektedirler.

Amerika Birleşik Devletleri'nde ortopedi ve travmatoloji eğitimi oldukça farklılıklar göstermektedir: öğrenciler, kolej nedeniyle İngiltere'ye kıyasla eğitimlerine dört yıl daha geç başlamakta, dolayısıyla uzmanlıklarını daha organize ve yoğun bir eğitimle beş yılın sonunda almaktadırlar. Potansiyel adaylar, United States Medical Licensing Examination (USMLE) sonuçları, yaptıkları araştırmalar, tavsiye mektupları ve müfredat dışı aktiviteleri ile değerlendirilerek kabul edilmektedirler. ilk yıl eğitimleri, genel cerrahi, plastik cerrahi, acil tıp ve anesteziyi içermektedir. İkinci yıldan itibaren, eğitim ve uygulamalarına şef asistan tarafından nezaret edilmekte ve bu çalışmalar usta-çırak ilişkisi ile yürütülmektedir. Tüm asistanlar hemşire ve tıp öğrencilerine eğitim vermektedirler. Tüm eğitim boyunca, kurum içi eğitim içi sınavlara, yeterlilik değerlendirmelerine ve yıllık ulusal sınava tabi tutulmaktadırlar; araştırma ve laboratuvar çalışmalarına dahil edilmekte ve programı tamamlamak için çalışmalarını sunmaları beklenmektedir. Asistanlıklarını tamamlamalarını takiben, akademik olarak ilerlemek isteyenler alt dal eğitimleri ile devam etmektedir. ABD'de de, çalışma saatlerinin sınırlandırılması ile asistanların çalışma ve eğitim saatleri etkilenmiştir; ancak bu, haftalık 80 saat düzeyindedir. Eğitiminin tamamlanmasını takiben, ortopedi uzmanları iki aşamadan oluşan Ulusal Yeterlilik Sertifikası'nı almak üzere başvurabilirler. İkinci aşamaya ancak 22 aylık çalışma ve yeterli miktarda olgu sunduktan sonra girilebilmektedir. Adaylar, ikinci aşama sınavını eğitimlerini tamamladıktan ortalama beş yıl sonra almaktadırlar. ABD'de çalışan ortopedi uzmanlarının ancak $\% 74$ 'ü yeterlilik sertifikasına sahiptir.

İngiltere'de, tüm asistanlık eğitimi boyunca online olarak erişilen ve doldurulan bir kayıt defteri (logbook) bulunmaktadır. Bu sayede tüm asistanlar ve eğitilenler güncel olarak durumlarını takip edebilmekte, hatta benzer seviyedeki diğer klinik ve asistanlar ile durumlarını karşılaştırabilmektedirler. Bu kayıtlar, asistanın durumu ve müfredat uygunluğu açısından merkezi olarak da takip edilmektedir ve ulusal müfredata entegre bir yapıdadır. ABD'de benzer bir uygulama, sadece yeterlilik sınavının ikinci aşamasında kayıt altına alınan vakalar için yapılmaktadır.
AB çerçevesinde European Union of Medical Specialists (UEMS) ve European Board of Orthopaedics and Traumatology (EBOT) yukarıdaki örnekleri kendisine baz alarak yapılanma sürecini büyük ölçüde tamamlamak üzeredir. Biz de ülkemizde bu sisteme en hazır uzmanlık alanlarından biriyiz.

\section{ÜLKEMIZDE ORTOPEDI VE TRAVMATOLOJi EĞiTIMI YAPILANMASINDA TOTBID-TOTEK ETKISi}

TOTBID bünyesinde, 2001 yılında kurulan Türk Ortopedi ve Travmatoloji Eğitim Konseyi (TOTEK), “Ortopedi ve Travmatoloji Uzmanlık Eğitimi"nin kalitesinin yükseltilmesi ve eğitim birimlerinin kendi aralarındaki standardizasyonunun sağlanmasını amaçlamaktadır. TOTEK, Konsey Meclisi üyeleri arasından belirlenecek dokuz üye ve TOTBID Başkanı veya görevlendireceği bir TOTBID Yönetim Kurulu üyesi olmak üzere, toplam 10 üyeden oluşmaktadır. Amaçları ve hedefleri Türk Tabibleri Birliği (TTB) - Uzmanlık Dernekleri Eşgüdüm Kurulu (UDEK), Ulusal Yeterlik Kurulu (UYEK) ve Avrupa Tıp Uzmanları Birliği (UEMS) ile örtüşmektedir. TOTEK'in ilk temel hedefi olan çekirdek müfredat, konsey içinde yapılan çalışmalar, UEMS, International Society of Orthopaedic Surgery and Traumatology (SICOT), American Academy of Orthopaedic Surgeons (AAOS) ve American Board of Orthopaedic Surgery (ABOS) ile görüş alışverişleri gerçekleştirilmiştir.

Asistanların alması gereken asgari eğitimin içeriğini, pratik uygulamaları, edinmesi gereken tutum ve davranışları kapsayan bu çalışmalar, bunların nasıl gerçekleştirileceğini belirlemeyi hedeflemektedir. 2001-2003 yılları arasındaki ilk dönemde, Türkiye'deki eğitim kurumlarının envanteri, çekirdek eğitim müfredatı ve sınavlar için ilk çalışma grupları oluşturularak temeller atılmıştır. ${ }^{[3]}$ Daha sonraki yıllarda, öncelikle eğitim müfredatının oluşturulması, müfredata uygun kursların açılması ve beş yıllık süreçte asistanların bu kursları alması, ve tabii ki Ortopedi ve Travmatoloji Yeterlik Sınavı (TOTEK Sınavı - Board) yazılı ve sözlü kısımlarının oluşturulması aşamaları büyük bir başarı ile gerçekleştirilmiştir. TOTEK, ilk olarak 2002 yılında, o dönemki eğiticilere bir kereye mahsus verilen Yeterlik Belgesi ile başlayan ve 2003 yılından itibaren de başarı ile sınavlarını her yıl düzenli olarak gerçekleştiren bir yapıya kavuşmuştur.

Uzmanlık eğitiminin standart hale getirilmesi için kurumların akreditasyonu son derece önemlidir. TOTEK bu amaçla, kurumların eğitim açısından değerlendirilmesini, onaylanmasını ve yetkilendirilmesini sağlamaktadır. İç, dış ve bağımsız denetçiler ile kurum ziyaretleri yaparak ve eğiticileri eğiterek standardizasyon sağlanmaya çalışılmaktadır. TOTBID-TOTEK tarafından 2012 yılında başlatılan bu faaliyet, TTB-UDEK'in belirlediği kurum 
ziyaretleri ve akreditasyon programı esasları çerçevesinde gerçekleştirilir. ${ }^{[4]}$ Dört kurum, 2014 yllı itibariyle TOTEK tarafindan akredite edilmiş durumdadır. ${ }^{[5]}$

Uzmanlık Eğitimi Gelişim Sınavı, tanımlanan standart eğitime ulaşmak için kullanılan araçlardan biridir. Her yıl yaklaşık 800 asistanın katılımıyla yapılan bu merkezi ulusal sınavla kliniklerin ve asistanların düzeyleri değerlendirilmektedir. Bu, İngiltere ve ABD'de de bulunan örnekleri gibi bir "yetkinlik saptama" sınavıdır. TOTEK, asistanların eğitimleri boyunca almaları gereken temel becerileri belirlemenin yanında, bunlara ulaşılabilmesi için gerekli kursların da gerçekleştirilmesini sağlamaktadır. Bu sayede, asistanlar kendi kurumları içerisinde yeterli eğitimi alamasalar dahi, kurslar sayesinde eğitimde boşlukların oluşmaması sağlanmaktadır. Asistanların, eğitimlerinin hangi yılında hangi becerilere sahip olması gerektikleri, dolayısıyla hangi kurslara katılımlarının sağlanması gerekliliği belirlenmiş durumdadır. Ayrıca, Temel Bilimler ve Araştırma Okulu, Çekirdek Eğitim Programı (ÇEP) Kursu ve TOTEK tarafından desteklenenler olmak üzere üç kategoride kurslar yıllık takvime göre düzenlenmiştir. Oluşturulan ulusal ÇEP programı, Sağlık Bakanlığı ile koordineli olarak gerekli kurullardan geçirilmiş ve TOTBID-TOTEK'in hazırladığı program Tıpta Uzmanlık Kurulu'nda Ulusal ÇEP programı olarak da kabul edilmiştir. Bugüne kadar TOTEK sertifikasını almış toplam 758 kişi vardır. Bunların ilk 269'u sınavsız olup geri kalanları sınavla belgelendirilmiştir.

Yetkilendirme sürecinde, eğitim içi sınavlar ilk basamağı, uzmanlık sonrası yapılan yeterlilik sınavı ve belirli bir süre sonra gerçekleştirilen yeniden belgelendirme (resertifikasyon) ise diğer önemli basamakları oluşturmaktadır. Yeniden belgelendirme, ABD'de 1971'den beri gerçekleştirilmektedir. illk yeterlilik belgesini aldıktan sonra 10 yılı geçen ortopedi uzmanlarının yeterlilikleri, 2012 yılından itibaren yeniden değerlendirilerek belgelendirilmiştir. 2014 yılı itibarı ile tekrar belgelendirmeye başvuran TOTEK üyesi, toplam 71 kişidir.

TOTEK, kurulduğu 2001 yılından itibaren UEMSEBOT ile yakın ilişkiye geçmiş, her yıl yapılan toplantılara düzenli olarak katılmıştır; kurul içindeki yerini sağlamlaştırmış ve Türkiye AB üyesi olmadığı halde, 2006 yılından itibaren TOTEK, sertifikalı üyelerini EBOT sınavlarına sokma hakkını elde etmiştir. Bugüne kadar 31 kişi EBOT sınavında başarılı olarak Avrupa Ortopedi ve Travmatoloji Yeterlik Belgesi almıştır. Türkiye'den sınav yapıcılar da bu sınavda yer almaktadırlar.

TOTEK tarafından gerçekleştirilen bütün bu çalışmaların iki yıllık dönemler halinde hazırlanan raporları, dönem kitapları olarak yayımlamaktadır. ${ }^{[3]}$
TOTBID-TOTEK'in bu noktalara gelmesindeki en büyük başarı, geçmiş TOTEK başkanları ve yönetim kurulu üyeleri ile onlara her türlü desteği veren tüm geçmiş TOTBiD başkanları ve yönetim kurullarıdır. Onlara buradan teşekkürü bir borç bilirim.

\section{GELECEĞE YÖNELIK ÖNERILER}

Amaç, Türkiye'de uzmanlık eğitimi veren tüm kuruluşlarda (eğitim hastaneleri, devlet ve vakıf üniversiteleri) standart bir uzmanlık eğitimi verilmesi, iyi ve güvenilir ortopedi ve travmatoloji uzmanı yetiştirilmesidir. Gelinen noktada, ortopedi ve travmatoloji uzmanlık eğitimi, $A B D$ ile örtüşen bir eğitim ve değerlendirme düzeyine erişmiş durumdadır.

Bu amaçla, şimdiye kadar olduğu gibi, asistanların uzmanlık eğitimlerinin son yılında TOTEK sınavının yazılı kısmına, uzmanlık sonrası da sözlü kısmına girerek TOTEK sertifikası almaları ve bu sertifikanın da gerek SB gerekse YÖK tarafından tanınmasıdır.

Uzmanlık Eğitimi Gelişim Sınavı'nın YÖK ve Sağlık Bakanlığı gibi resmi kurumlarca tanınması ve eğitim kurumlarının yeterliliği için bir ölçüt olarak kabul edilmesi son derece önemlidir ve akreditasyonu direkt olarak etkilemelidir. Kurumların elde ettikleri asistan sınav sonuçları, bir üst kurul tarafından değerlendirilmeli, devamlı düşük sonuçlar elde eden kurumların akreditasyonu da bir süre sonra tekrar değerlendirilmelidir.

Asistan karnesi, bu denetimlerin temel yapı taşlarından biridir. İngiltere örneğinde olduğu gibi elektronik ve online asistan karnelerinin olması, hem kişilerin kendi durumlarını görmeleri hem de kurumların kendilerini değerlendirmesi açısından çok önemlidir. Asistanların eğitim durumlarının resmi kurumlarca takip edilmesi bu sayede mümkün olacaktır.

Türkiye'de, diğer dallar göz önüne alındığında, eğitim açısından ortopedi ve travmatoloji en iyi organize olmuş dal durumundadır.

On beş yıla varan bu sistemin gelecekte korunması ve daha da ileriye götürülmesi, Ortopedi ve Travmatoloji Ailesi'nin en önemli sorumluluğudur.

\section{KAYNAKLAR}

1. Sağlık Bakanlığı, Yüksek Öğretim Kurumu, Maliye Bakanlığı ve Kalınma Bakanlığı. Türkiye'de Sağlık Eğitimi ve Sağlık İnsangücü Durum Raporu; 2014.

2. Lewis C, Mauffrey C, Lewis AC, Whiting F. Orthopaedic training the world over. Bone and Joint 360 2014;3:2-7.

3. TOTEK Dönem Kitapları. http://totek.totbid.org.tr/Content. aspx?p=2051

4. TTB-UDEK / UYEK Eğitim Kurumlarını Ziyaret Programının Esasları. http://wnw.ttb.org.tr/udek/index.php?option=com_content\&view= article\&id=205:ttb-udek--uyek-em-kurumlarziyaret-program-esaslar\& catid=79: mevzuat\&ltemid=146

5. Kurum Ziyaretleri ve Akreditasyon. http://totek.totbid.org.tr/ Content.aspx?p=2082 